do, in fact, occur in nature but suggests various ways in which they might arise.

This book can be recommended with few reservations to those workers who require a useful reference to a range of nucleic acid antagonists. It is also quite easy to read and treats an often complicated subject in a clear and straightforward way.

P. N. MAGEE

\section{CHRISTMAS CHEER}

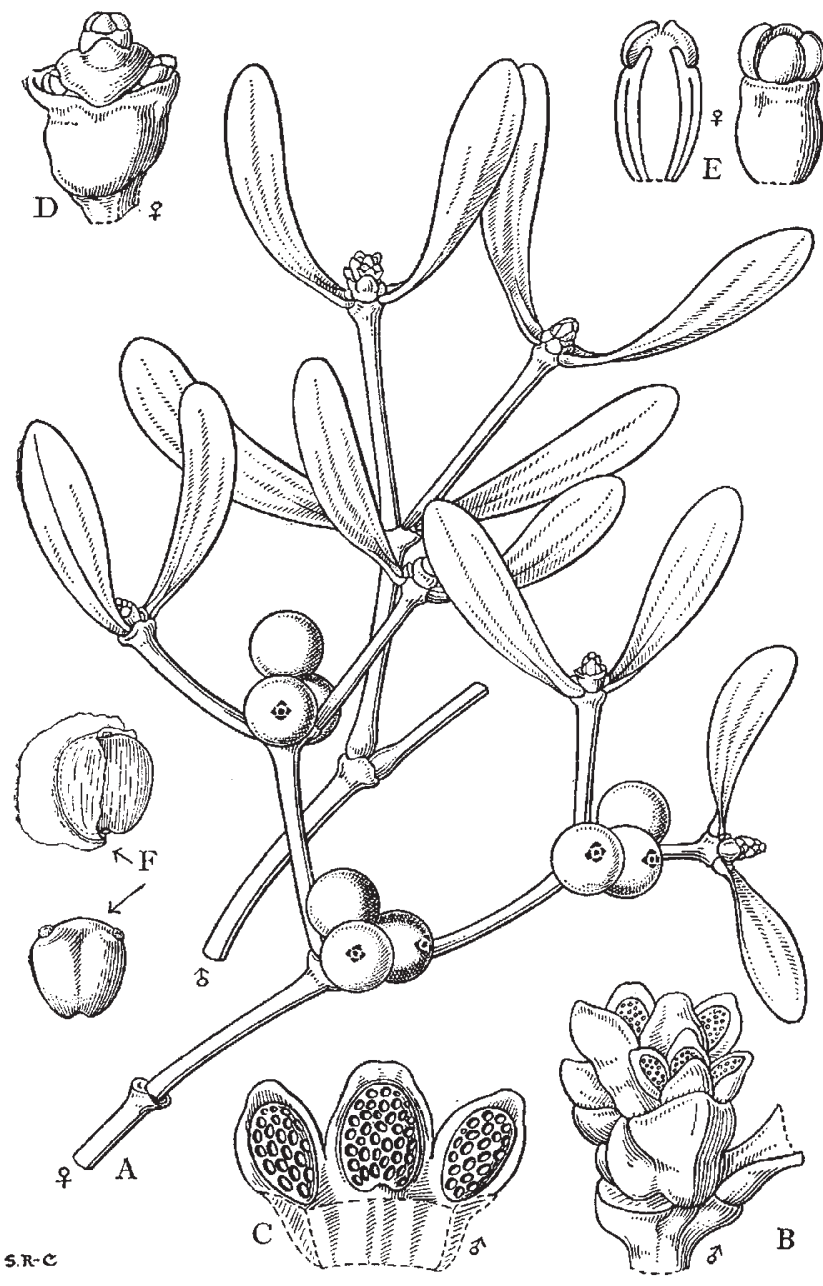

The various parts of the male and female mistletoe plant (Viscum album) as drawn by Stella Ross-Craig of the Royal Botanic Gardens, Kew. Part XXVI of her Drawings of British Plants now published includes representatives of the families Polygonaceae, Thymelaeaceae, Elaeagnaceae, Loranthaceae,

Santalaceae, Euphorbiaceae, and Buxaceae growing naturally in the British Isles (Bell: London, September 1969, 16s).

\section{COLLATION OF SPORE RESEARCH}

The Bacterial Spore

Edited by G. W. Gould and A. Hurst. Pp. xiv +724 . (Academic Press: New York and London, September 1969.) $180 s ; \$ 27.50$.

IN a book of this scope, there is inevitably some overlap between chapters; the editing, however, has reduced reiteration to a minimum. All aspects of sporulation are admirably treated in the early chapters and a logical sequence of events clearly emerges. A comment on the possible mechanism of transport of metabolites from the sporangial cell into the forespore might have been of interest.

The variety of hypotheses on the dormancy, low permeability and heat stability of the mature spore are clearly described. Of those relating to heat resistance, the protein-Ca-DPA model appears with justice more than once; perhaps the ionic effects reported by Sadoff and related to dimer-monomer interconversion of glucose dehydrogenase might have some discussion.

Lewis suggests that the cationic exchange property of the dormant spore (Alderton and Snell) and its involvement in heat resistance can be visualized in his own concept of the pressure generating cortex. Indeed, it is noticeable throughout all relevant chapters that the contractile cortex hypothesis can be introduced in considerations of permeability, dormancy and germination. There is an apparent slight misinterpretation of Lewis's hypothesis on page 97 .

To explain the biological role of the spore, an interesting new hypothesis is presented by Bernlohr and Leitzmann. The induction of germination by L-alanine, and the like, remains obscure. A possible germination sequence beginning with activation by reduction of coat disulphide bonds, entry to the cortex of lytic enzyme (possibly released by a product of metabolism of a germinant and destruction of the contractility of the cortex, again draws on the Lewis hypothesis.

The later chapters include a comprehensive description of the development of insect control by strains rif $B$. popilliae and $B$. thuringiensis and also an outline of the medical and veterinary significance of spore-forming bacteria, mainly clostridia. The importance of sporeformers in food spoilage is deliberately treated in a general way and makes a cogent argument against too great is too early a relaxation of current heat and curing procedures. The kinetics of heat and radiation sterilization of spores is concisely presented and the treatment of spore resistance to physical and chemical agents is complete and rery well documented.

The chapter bibliographies are extensive, the subject index is adequate and the presentation of the author index is most welcome. There could perhaps have been an expansion of one or two items, for example, the quantitative effects of oxygen and carbon dioxide on germination, especially of clostridia. The glossary of conventions, a pleasant idea, is incomplete (for example, PFK, DAB and FMN), and in the text diaminobutyric acid appears variously as DAB or DBA, whilst TCA is made to refer to trichloroacetic acid as well as to the Krebs cvele. I noticed no more than a dozen errata.

The book appears at a most suitable time and it is possibly the last feasible attempt at a comprehensive collation of spore research. It should appear in all relevant libraries and will spend little time on the shelves. G. J. Ricisy

\section{LITTLE STUDIED PLANKTON}

\section{Annotated Index of Fossil and Recent Silicoflagellates and Ebridians}

With Descriptions and Illustrations of Validly Proposed Taxa. By Alfred R. Loeblich III, Laurel A. Loeblich, Helen Tappan and Alfred A. Loeblich, jun. (The Geological Society of America, Memoir 106.) Pp. xi +319 with 53 plates. (Geological Society of America: Colorado, 1968.) $\$ 12.50$

Sillicoflagellates and ebridians are not at all well known among either palaeontologists or biologists. Nevertheless, they are not rarities in modern plankton nor in sediments of Cretaceous or Tertiary age, and locally they mav be quite abundant.

Although both fossil and living silicoflagellates have been known for more than a century, there has been little sus- 